\title{
ANION-EXCHANGE SYNTHESIS OF COPPER FERRITE POWDERS
}

\author{
T. V. Trofimova, ${ }^{1}$ S. V. Saikova, ${ }^{1,3}$ M. V. Panteleeva, ${ }^{2,4}$ G L. Pashkov, ${ }^{2}$ and G N. Bondarenko
}

\begin{abstract}
Amethod is proposed for synthesizing copper ferrite, consisting in anion-exchange precipitation of copper (II) and iron (III) from solutions oftheir salts in the presence oftartrate ions as complexing agents followed by cal cination of the obtained precipitate. The precursors and the products of their heat-treatment or studied by means of chemical, complex thermal and $x$-ray phase analyses, IR spectroscopy, scanning electron microscopy, and $x$-ray spectral microanalysis; the magnetic properties of the obtained samples were also studied. It was determined that a ferromagnetically ordered phase is present in the synthesized materials and their magnetic properties are close to those of bulk $\mathrm{CuFe}_{2} \mathrm{O}_{4}$.
\end{abstract}

Key words: copper ferrite, synthesis, anionite, magnetic particles.

Copper ferrite $\mathrm{CuFe}_{2} \mathrm{O}_{4}$ is one of the magnetic materials which are in greatest demand. Interest in ferrites arose in connection with the wide use of these compounds in different microwave devices, in radio electronics and computer engineering, and in biology and medicine. $\mathrm{CuFe}_{2} \mathrm{O}_{4}$ is also used to develop high-density information carriers, ferromagnetic liquids, catalysts, magnetic separation, magnetic resonance tomography, and gas sensors [1-3].

The most widely used methods of obtaining copper ferrite powders are solid phase and sol-gel methods as well as coprecipitation from water solutions. In most cases solid phase synthesis of copper ferrite by the method used in the production of ceramic articles incorporates several stages, such as homogenization of $\mathrm{CuO}$ and a- $\mathrm{Fe}_{2} \mathrm{O}$, powders, compaction of reagents, and finally prolonged multistep heattreatment at high temperatures $[3,4]$.

However, the problem of obtaining nano-sized materials from clinkers obtained in this manner is very problematic and is solved with difficulty by means of grinding of the ready ferrite in a ball mill for many hours. In addition, a product with inadequate chemical uniformity, contaminated by the milling-body material, as well as unreacted copper and iron oxides is formed. For example, the authors of [4] re port that they obtained a pure $\mathrm{CuFe} \mathrm{O}_{4}$, phase only after fir-

Siberian Federal University, Krasnoyarsk, Russia.

Institute of Chemistry and Chemical Technology, Krasnoyarsk Regional Center for Collective Use of the Siberian Branch of the Russian Academy of Sciences, Krasnoyarsk, Russia.

E-mail: ssai@mail.ru.

E-mail: vp414@mail.ru. ing for $20-28 \mathrm{~h}$ at $850-1000^{\circ} \mathrm{C}$ o f pre-mixed (in ethyl alcohol) and briquetted at pressure $10 \mathrm{MPa}$ initial powders of $\mathrm{CuO}$ and $\mathrm{Fe}_{2} \mathrm{O}$, with a mineralizer (potassium chloride).

The drawbacks of the sol-gel method include the synthesis time owing to the transition from a colloidal solution (sol) to a colloidal precipitate (gel) and the high cost of the re agents used. In [5] it is reported that a sol was obtained from a mixture of solutions of $\mathrm{Cu}$ (II) and Fe(III) nitrates by the ac tion of ammonia in the presence of polyvinyl alcohol. Since the obtained sol was contaminated with large amount of im purities it was first dried for $12 \mathrm{~h}$ at $120^{\circ} \mathrm{C}$ and then heat-treated in air up to formation of free-flowing powder, sintered first at $500^{\circ} \mathrm{C}$ in order to decompose the impurities and then once again at $1000^{\circ} \mathrm{C}$ after pressing.

In [6] polyacrylic acid was used as a chelating agent. In the synthesis process the sol was evaporated in $10 \mathrm{~h}$ up to complete removal of water and gel formation. After calcina tion of the gel at $400^{\circ} \mathrm{C}$ for $2 \mathrm{~h}$ a dark brown precipitate was obtained. On the basis of the X P A data one cannot talk about obtaining a pure phase of copper ferrite because the authors did not identify all peaks in the $x$-ray diffraction pattern.

In [7] citric acid and a solution of ammonia were added into the system up to $\mathrm{pH}=7$; the system was intensely mixed up to gel formation and dried at $90^{\circ} \mathrm{C}$. The obtained powder was purified using acetone and toluene and fired at $800^{\circ} \mathrm{C}$ for 2 h. As a result a pure $\mathrm{CuFe} \mathrm{F}_{2}$ phase was obtained.

The chemical precipitation method makes it possible to obtain uniform fixtures that do not require careful grinding and mixing. This method is quite simple and does not require expensive apparatus; it also makes it possible to lower the 
heat-treatment temperature, but the precipitates formed in this case, as a rule, are contaminated with the precipitant ions $[8,9]$, which negatively impacts the properties of the obtained materials and the interaction of precursors, so that prolonged washing of the precipitate is required. For example, in [8] it was not possible to obtain a pure phase of copper ferrite (the product is contaminated with the oxides $\mathrm{Cu} O$ and a- $\mathrm{Fe}_{2} \mathrm{O}_{3}$ ) even after triple washing with hot water and then ethanol and acetone, followed b y calcination at $700^{\circ} \mathrm{C}$. More careful washing and longer firing at temperature $800-1200^{\circ} \mathrm{C}$ were required for complete formation o f cop per ferrite [9].

It is well known that many magnetic parameters of ferrites are structure sensitive, so that the production of a pure phase of copper ferrite with uniform composition and morphology is a real problem.

We have shown previously [10-13] that anion-exchange precipitation (a term introduced by A. I. Vulikhov [14]), i.e. using an anionite in the $O H$ or salt form, makes it possible to perform synthesis under stationary conditions and to obtain products consisting of particles with uniform composition, size, and shape, which, in addition, do not contain impurities of the precipitant cations and anions of the initial salt and therefore do not require multiple washing and purification operations. This method also eliminates the use of ex pensive equipment, high labor-intensiveness, and long synthesis times.

The aim ofthe present work is to find optimal conditions for synthesizing copper ferrite by the method of anion-exchange precipitation from a solution of a mixture ofiron (III) and copper (II) salts with the aid of strongly basic anionite AV-17-8 in the 0 H form and to study the composition, struc ture, and properties of the formed product.

\section{EXPERIMENTAL PART}

The strongly basic anionite AV-17-8 in the $0 \mathrm{H}$ form with grain size $0.25-0.5 \mathrm{~mm}$ and high Donnan potential impeding the penetration of cations into the sorbent phase was used in this work. The initial anionite in the $\mathrm{Cl}$ form was treated with $1 \mathrm{M} \mathrm{NaOH}$ for $1 \mathrm{~h}$ and then five or six times with $2 \mathrm{M}$ $\mathrm{NaOH}$ also for $1 \mathrm{~h}$. Next, the anionite was washed with water to $\mathrm{p} \mathrm{H}=6-7$ and dried at temperature $60^{\circ} \mathrm{C}[10,11]$. Its full exchange capacity in terms of $0.1 \mathrm{M} \mathrm{HCl}$ under static conditions $(2.28 \mathrm{mmol} \cdot \mathrm{eqv} / \mathrm{g})$ was determined as described in [12].

Anion-exchange precipitation of the precursor of copper ferrite was performed by two methods:

- two-step precipitation: $20 \mathrm{~g}$ of anionite swollen in water was put into contact with $16.6 \mathrm{ml}$ of $0.25 \mathrm{~m} \mathrm{CuCl}$, for $20 \mathrm{~min}$ and then $33.4 \mathrm{ml}$ of $0.25 \mathrm{M}$ solution of $\mathrm{FeCl}_{3}$ and mixed for another $3 \mathrm{~h}$ in a shaker at the rate $120 \mathrm{~min}^{-1}$ at $23^{\circ} \mathrm{C}$. The anionite was separated, the mixture passed through a sieve with $0.16 \mathrm{~mm}$ in diameter openings. Centrifuging was performed in order to separate the precipitates.
The obtained precipitates were dried at $80^{\circ} \mathrm{C}$ in a drying cab inet and calcinated at temperature $700-900^{\circ} \mathrm{C}$ for $3 \mathrm{~h}$;

- single-step precipitation: $20 \mathrm{~g}$ of anionite swollen in water was put into contact with a solution of a mixture of salts $(16.6 \mathrm{ml}$ of $0.25 \mathrm{M} \mathrm{CuA}$ and $33.4 \mathrm{~mm}$ of $0.25 \mathrm{M} \mathrm{FeA}$ (where $\mathrm{A}=\mathrm{NO}_{3}, \mathrm{Cl}^{\wedge}, 1 / 2 \mathrm{SO}^{\wedge}$ )) also containing $5 \mathrm{ml}$ of a $0.25 \mathrm{M}$ solution K S C N or N a ${ }_{2} \mathrm{C}_{4} \mathrm{H}_{4} \mathrm{O}_{6}$ and mixed for $3 \mathrm{~h}$ in a shaker at the rate $120 \mathrm{~min}^{-1}$ at $23^{\circ} \mathrm{C}$. The obtained precipitates were dried at $80^{\circ} \mathrm{C}$ i n a drying cabinet and calcinated at temperature $950^{\circ} \mathrm{C}$ for $3 \mathrm{~h}$.

The concentration of copper (II) and iron (III) in the solutions was determined by means of complexometric titration and atomic-absorption spectroscopy. X-ray phase analysis (DRON-3 diffractometer, CuKa-radiation) and IR-Fourier spectroscopy (Vector 22 IR-Fourier-spectrometer (Bruker Company)) were used to identify the products of synthesis. Photomicrographs were obtained in secondary electrons in a Hitachi AS-5500 scanning electron microscope with ac celerating voltage $30 \mathrm{kV}$ as well as in back-reflected elec trons on a Hitachi TM-3000 tabletop microscope with a Quantax 70 (Bruker) system for performing x-ray fluores $\neg$ cence microanalysis.

Complex thermal analysis of the precursor was performedwith a S TA 449 C Jupiter (NETZSCH) simultaneous thermal analyzer, combining simultaneous measurement of the mass changes (thermogravimetry) and heat fluxes (differ $\urcorner$ ential scanning calorimetry), combined with a Q M S 403 C A, olos (NETZSCH) quadrupole mass spectrometer for ana lyzing the gases released upon heating of the samples from 40 to $1200^{\circ} \mathrm{C}$ at the rate $10 \mathrm{~K} / \mathrm{m}$ in in a dynamic atmosphere of air (gas $\mathrm{flow}$ rate $30 \mathrm{ml} / \mathrm{min}$ ).

The magnetic circular dichroism (MCD) was measured using a setup built in the laboratory of the physics of mag $\neg$ netic phenomena at the Institute of Physics of the Siberian Branch of the Russian Academy of Sciences - FITs KNTs SO R A N , in the spectral range $(10-26) \times 10^{3} \mathrm{~cm}^{-1}$ in mag $\neg$ netic fields up to $1.2 \mathrm{~T}$ at $300 \mathrm{~K}$ and to $0.5 \mathrm{~T}$ for $10 \mathrm{wer}$ tem $\neg$ peratures. The accuracy of the measurements was equal to $10^{-4}$ for MCD, \pm 10 0e for the magnetic field, and $\pm 1 \mathrm{~K}$ for the temperature.

To determine the total precipitation time of copper (II) and iron (III) hydroxides the change of the electrical conduc tivity of the systems anionite-copper salt and anionite-iron salt in time was studied (A N I N 4120 conductometer).

\section{DISCUSSION}

The process of anion-exchange precipitation of copper and iron can be described by the equation

$$
5 \mathrm{R}-\mathrm{OH}+\mathrm{CuA}+\mathrm{FeA}_{3}=5 \mathrm{R}-\mathrm{A}+\mathrm{Cu}(\mathrm{OH})_{2}+\mathrm{Fe}(\mathrm{OH})_{3},
$$

where A is the anion of the initial salt $\left(\mathrm{NO}_{3}, \mathrm{Cl}^{*}, 1 / 2 \mathrm{SO}^{3}\right)$; $\mathrm{R}-\mathrm{OH}$ and $\mathrm{R}-\mathrm{A}$ denote the anionite in the $\mathrm{OH}-$ and anionic forms, respectively. 
Fig. 1. Time variation of the properties of the anionite - copper salt system (curve 1 ) and the system anionite - iron salt (curve 2) without complexing agents $(a, b)$ and in the presence of sodium tartrate $(c, d)$ : a, c) variation of electrical conductivity; $b, d)$ variation of the degree ofprecipitation ofions.
Electrical conductivity, $\mathrm{mS} / \mathrm{m}$

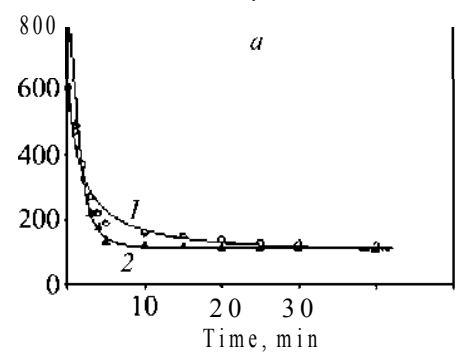

Electrical conductivity, $\mathrm{mS} / \mathrm{m}$

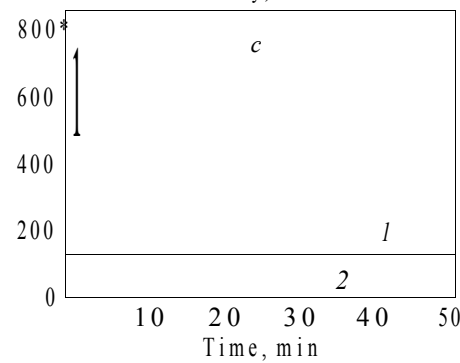

Degree of precipitation, \%

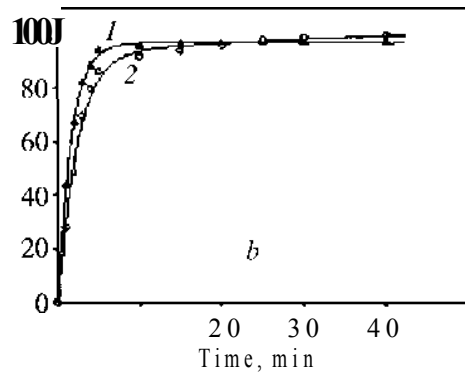

Degree of precipitation, \%

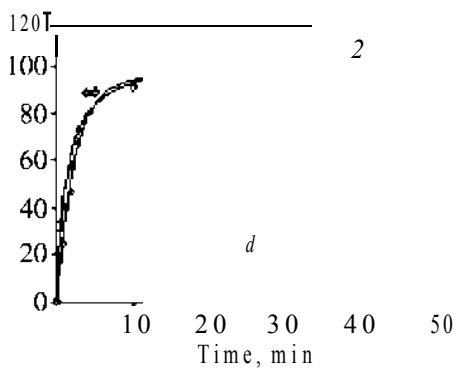

The synthesis of copper ferrite was performed from a mixture of $0.25 \mathrm{M}$ solutions of copper and iron chlorides taken in the molar ratio $1: 2$. The obtained results, presented in Table 1 (experiment 2), attest that the molar ratio $\mathrm{Cu}^{2}+/ \mathrm{Fe}^{3}+$ in the obtained precursor (0.33) does not correspond to the stoichiometric value $(0.5)$; the yield of the product was equal to $74 \%$, which indicates incomplete precipita tion of copper and iron. In addition, according to the X P A data, after calcination of the precipitate at $900^{\circ} \mathrm{C}$, aside from $\mathrm{CuFe} \mathrm{O}_{4}$, the product contains hematite $\mathrm{Fe}_{2} \mathrm{O}_{3}$, (the reflec $\neg$ tions in the $x$-ray diffraction pattern that correspond to the interlayer distances 2.70 and 2.21) [15].

To obtain a pure phase of copper ferrite it is necessary to obtain in the product of precipitation the stoichiometric ratio $\mathrm{Cu}^{2}+/ \mathrm{Fe}^{3}+$, i.e. to attain its complete precipitation. To achieve this result the reaction conditions must be closely monitored. Additional difficulties are associated with the different va lues of the solubility product of copper hydroxide (II) and iron hydroxide (III). The computed pH at the start of precipitation of copper when using for synthesis the concentration of metal ions is equal to $5.7\left(\mathrm{SP}\left(\mathrm{Cu}(\mathrm{OH})_{2}\right)=2.2 \times 10^{-20}\right)$ and the $\mathrm{pH}$ at the onset of the precipitation of iron about 2 $\left(\mathrm{SP}\left(\mathrm{Fe}(\mathrm{OH})_{3}\right)=6.3 \times 10^{-38}\right)$, i.e. iron precipitates sooner and more completely than copper.

The time dependences of the degree of precipitation of copper and iron ions are presented in Fig. $1 \boldsymbol{a}$ and $\boldsymbol{b}$. These dependences were obtained by measuring the electrical con 7 ductivity of the systems anionite-copper salt and anioniteiron salt. It is evident that $5 \mathrm{~min}$ is sufficient for practically

TABLE 1. Conditions and Results of Anion-Exchange Synthesis of Copper Ferrite $(\mathrm{n}(\mathrm{Cu}) / \mathrm{n}(\mathrm{Fe})=3.9 / 7.8 \mathrm{mmol})$

\begin{tabular}{|c|c|c|c|c|c|c|c|c|}
\hline No.* & Initial salts & $\begin{array}{c}\boldsymbol{n}\left(\mathrm{SCN}^{-}\right) \\
\quad \mathrm{mmol}^{-1}\end{array}$ & $\begin{array}{c}n(\mathrm{C} 4 \mathrm{H} 406) \\
\mathrm{mmol}\end{array}$ & $\begin{array}{l}\text { Elemental ana } \\
\text { Molarratio } \\
\text { Cu2+/Fe3+ }\end{array}$ & of precursor & $\begin{array}{l}\text { Product } \\
\text { yield, } \%\end{array}$ & 'fire we & $\begin{array}{c}\text { Composition of products } \\
\text { (XPAdata; see Fig. } 2 \text { ) } \\
{[15-17]}\end{array}$ \\
\hline \multicolumn{9}{|c|}{ Two-step precipitation } \\
\hline \multirow[t]{3}{*}{1} & $\mathrm{CuCl}_{2}+\mathrm{FeCl}_{3}$ & - & - & 0.42 & $\mathrm{No}_{0}$ & 81 & 700 & $\mathrm{CuO}, \mathrm{Fe}_{2} \mathrm{O}_{3}, \mathrm{CuFe} \mathrm{O}_{2}$ \\
\hline & & & & & & & 900 & $\mathrm{CuFe} \mathrm{O}_{4}, \mathrm{Fe}_{2} \mathrm{O}_{3}$ \\
\hline & \multicolumn{8}{|c|}{ Single-step precipitation } \\
\hline 2 & $\mathrm{CuCl} l_{2}+\mathrm{FeCl}_{3}$ & - & - & 0.33 & $\mathrm{~N}_{0}$ & 74 & 950 & $\mathrm{CuFe}_{2} \mathrm{O}_{4}, \mathrm{Fe}_{2} \mathrm{O}_{3}$ \\
\hline 3 & $\mathrm{Cu}\left(\mathrm{NO}_{3}\right)_{2}+\mathrm{Fe}\left(\mathrm{NO}_{3}\right)_{3}$ & 1.2 & - & 0.38 & $\mathrm{~N}_{0}$ & 80 & 950 & $\mathrm{CuFe}_{2} \mathrm{O}_{4}, \mathrm{Fe}_{2} \mathrm{O}_{3}$ \\
\hline 4 & $\mathrm{Cu}\left(\mathrm{NO}_{3}\right)_{2}+\mathrm{Fe}\left(\mathrm{NO}_{3}\right)_{3}$ & - & 1.2 & 0.46 & Traces & 93 & 950 & $\mathrm{CuFe} \mathrm{F}_{2}$ \\
\hline 5 & $\mathrm{CuCl}_{2}+\mathrm{FeCl}_{3}$ & - & 1.2 & 0.46 & $\mathrm{~N}_{0}$ & 86 & 950 & $\mathrm{CuFe}=0$ \\
\hline 6 & $\mathrm{CuSO}_{4}+\mathrm{Fe}_{2}\left(\mathrm{SO}_{4}\right)_{3}$ & - & 1.2 & 0.47 & $\mathrm{~N}_{0}$ & 98 & 950 & $\mathrm{CuFe}=$ \\
\hline
\end{tabular}

Number of experiment/sample. 


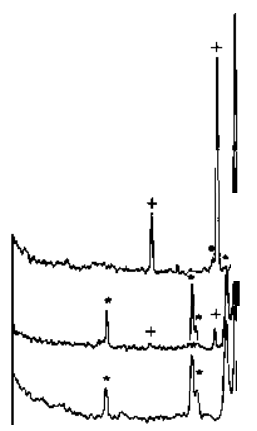

Sample 1

$\wedge 1\left(\mathrm{~T}_{\mathrm{fir}}=700^{\circ} \mathrm{C}\right)$

Sample

$\left(7>_{i, \mathrm{e}}=900^{\circ} \mathrm{C}\right)$

Sample 2

Sample 3

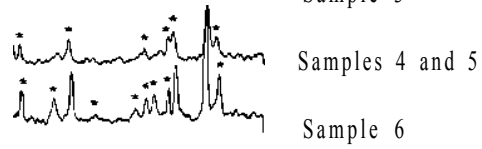

$\begin{array}{llllllll}10 & 20 & 30 & 40 & 50 & 60 & 70 & 20, \mathrm{deg}\end{array}$

Fig. 2. X-ray diffraction pattern of the samples (experiments) 1-6 (the numbers on the curves correspond to the numbers of the samples in Table 1): *) $\mathrm{CuFe}_{2} \mathrm{O}_{4}$; +) $\mathrm{Fe}_{2} \mathrm{O}_{3}$; •) $\mathrm{CuO}$.

complete precipitation of iron, and $15 \mathrm{~min}$ are required for precipitation of copper.

$0 n$ the basis of the fact that the reaction rate and $\mathrm{pH}$ for the onset of copper and iron precipitation are different a two-step method of synthesis was used. In this method, first, the anionite is put into contact with the copper solution for $20 \mathrm{~min}$, after which a solution of iron salt is added into the system. The obtained results, which are presented in Table 1 (experiment 1), showed that even though the molar ratio $\mathrm{Cu}^{2}+/ \mathrm{Fe}^{3}+$ is close to stoichiometry in the precursor (0.42), according to X P A data (Fig. 2, curve 1), the product obtained after calcination at $900^{\circ} \mathrm{C}$ contains aside from the main cop per ferrite phase the impurity $\mathrm{Fe}_{2} \mathrm{O}_{3}$. Probably, the presence of hematite in the product can be explained by a reduction of the activity of the copper phase of the precursor, which as a result of the rapidly advancing process of dehydration of $\mathrm{Cu}(\mathrm{OH})_{2}$ is $\mathrm{much}$ less active than $\mathrm{CuO}$. Thus, the two-step precipitation does not give the necessary result.

In order to decrease the precipitation rate of iron the ac $\neg$ tivity of the $\mathrm{Fe}^{3+}$ ions was decreased by introducing potas sium rhodanide or sodium tartrate (molar content $11 \%$ in terms of the sum of the metals), which form with iron (III) ions complexes of average strength (see Table 1, experiments 3-6). Iron (III) forms with rhodanide ions a series of $\mathrm{com}^{-}$ plexes with different charge, having the following instability constants: $\mathrm{K}_{1}\left([\mathrm{Fe}(\mathrm{SCN})]^{2}+\right)=9.3 \times 10^{-4} ; \mathrm{K}_{2}\left(\left[\mathrm{Fe}(\mathrm{SCN})_{2}\right]+\right)=$ $4.7 \times 10^{-5} ; \mathrm{K}_{3}\left(\left[\mathrm{Fe}(\mathrm{SCN})_{3}\right]\right)=2.3 \times 10^{-5} ; \mathrm{K}_{4}\left(\left[\mathrm{Fe}(\mathrm{SCN})_{4}\right]^{\circ}\right)=$ $3.0 \times 10^{-5} \quad[18]$, from which the uncharged complex $\left[\mathrm{Fe}\left(\mathrm{SCN}_{3}\right]\right.$ is most stable; the stability of the copper complexes with $\mathrm{SCN}^{-}$is $10 \mathrm{~W}$.

For the indicated concentrations of the ligand and solu tion the positively charged and neutral iron complexes should dominate, but, as our studies have shown (see Ta-

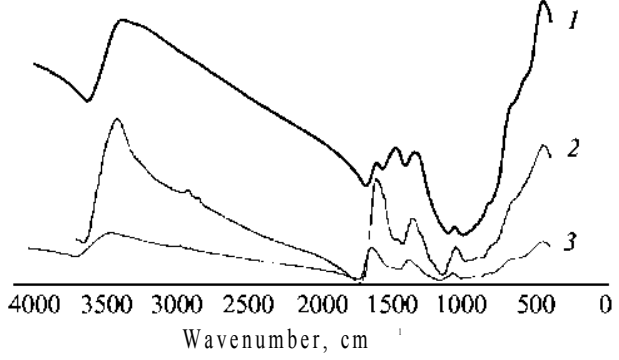

Fig. 3. IR spectra of the products of anion-exchange precipitation: 1) Fe(OH) ; 2) sample 4 (see Table 1); 3) sample 5 (see Table 1).

ble 1 , experiment 3 ) about $30 \%$ (molar fraction) of the iron transformed into the anionite phase, possibly as a result of the molecular sorption of the neutral complex. The ratio $\mathrm{Cu}^{2}+/ \mathrm{Fe}^{3}+$ in the precursor obtained in the presence of potassium rhodanide equals 0.38 , which does not correspond to the stoichiometric value. This product, according to X PA data (see Fig. 2, sample 3 ) is not a pure phase of copper ferrite.

In the experiments 4 - 6 (see Table 1) the precipitation was conducted from copper and iron nitrates, chloride, and sulfates in the presence of sodium tartrate. Iron (III) forms with the tartrate ions a series of complexes: $K_{1}([\mathrm{Fe}(\mathrm{Tart})]+)=$ $3.2 \times 10^{-8}, \mathrm{~K}_{2}\left(\left[\mathrm{Fe}(\mathrm{Tart})_{2}\right]^{-}\right)=1.4 \times 10^{-12}[18]$. At the pH of anion-exchange precipitation (about 7) in accordance with the distribution diagram (not presented) $\mathrm{Fe}^{3+}$ forms a mixed complex $[\mathrm{Fe}(\mathrm{OH})(\mathrm{Tart})]$, which has no charge. In the anionite phase the molar fraction of metal did not exceed $3 \%$.

According to Table 1 the molarratio $\mathrm{Cu}^{2+} / \mathrm{Fe}^{3+}$ in the obtained samples 4 - 6 is practically independent of the nature of the initial salt anion and is close to the stoichiometric value in copper ferrite $(0.46-0.47)$. According to the X P A data (see Fig. 2, samples 4 - 6) the products obtained after calcination at $950^{\circ} \mathrm{C}$ are a pure phase of copper ferrite.

The investigations showed that the maximum amount of copper and iron in the form of a precipitate was obtained when using sulfate solutions. On the whole the degree ofprecipitation decreases in the order $\mathrm{CuSO}>\mathrm{Cu}\left(\mathrm{NO}_{3}\right)_{2}>$ $\mathrm{CuCl} 1_{2}$, which coincides with the selectivity series of the anionite AV-17-8 to the given anions [19]. Thus, even though the type of anion of the initial copper (II) and iron (III) has no effect on the composition of the final product, in order to increase the degree of precipitation of copper (II) and iron (III) hydroxides it is expedient to conduct the anion-exchange precipitation process from sulfate solutions.

After calcination the precursors and samples were studied by physical methods of analysis. Figure 3 displays the IR spectra of the precursors (samples 4 and 5 , see Table 1) and iron (III) hydroxide obtained by anion-exchange precipitation. In the spectrum of the precursors we found absorption bands characteristic for the hydroxide $\mathrm{Fe}(\mathrm{OH})_{3}$ : the bands 3386 - $3467 \mathrm{~cm}^{-1}$ attest the presence of $\mathrm{OH}-\mathrm{groups}$ in them and the lines $1614-1700 \mathrm{~cm}^{-1}$ correspond to the deforma tion vibrations of free molecular $\mathrm{H}, \mathrm{O}$ and the bands in the in- 
Fig. 4. Photomicrographs of particles of samples 4 (a) (regions of $x$-ray spectral microanalysis are marked, see Table 2) and 5 (b) (see Table 1).
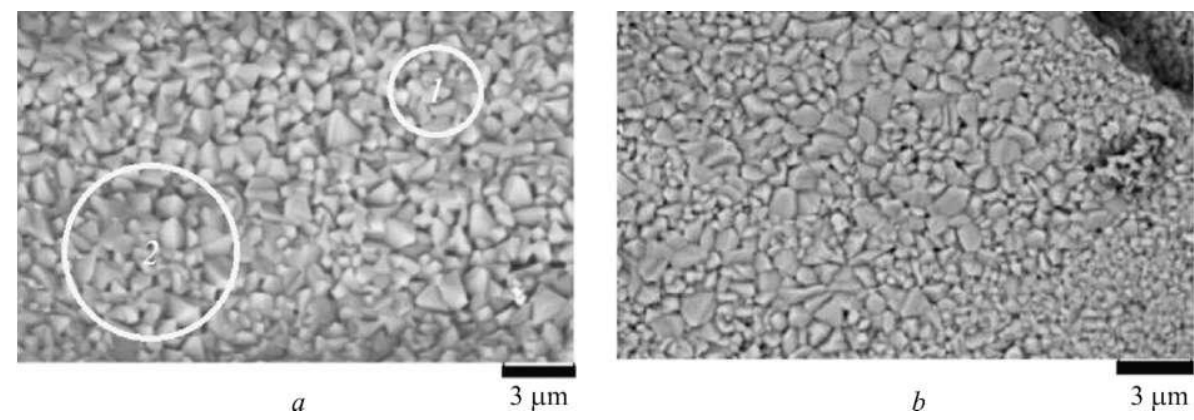

terval $454-467 \mathrm{~cm}^{-1}$ to the vibrations of the Fe-0 bond [20]. Some observed bands are shifted. This can be explained by the onset of the interaction of copper (II) and iron (III) hy droxides. No absorption bands corresponding $\mathrm{CuFe}, \mathrm{O}$, were found, and therefore the formation of copper ferrite does not occur at this stage. The absorption bands in the 2853 $2913 \mathrm{~cm}^{-1}$ for the samples 4 and 5 can be attributed to sym 7 metric and antisymmetric vibrations of $\mathrm{CH}_{2}$-groups, whose source could be sodium tartrate. The problem of or ganic-phase impurities is eliminated by subsequent calcina 7 tion of the precursor.

Complex thermal analysis of the precursor obtained in experiment 4 (see Table 1) showed that several thermal ef $\neg$ fects are observed in the DSC curve: an endo effect peaking at temperature $1016.8^{\circ} \mathrm{C}$, ow ing to water losses; exothermal effects near 217.2 and $268.8^{\circ} \mathrm{C}$, which are associated with the release of carbon dioxide; and, an exo-effect peaking at $503.3^{\circ} \mathrm{C}$, corresponding to the removal N $0_{2}$. Thus, small amounts of impurity carbonates, whose source is an anionite, and traces of nitrate ions, which are completely removed with subsequent calcination of the sample, are present in the precursor. A thermal effect due to the crystallization of $\mathrm{CuFe} \mathrm{O}_{4}$ is not observed.

According to scanning electron microscopy (SEM) (Fig. 4) the copper ferrite particles obtained in the experiments 4 and 5 have a similar morphology (octahedra) and the same size of about 1 цш. X-ray spectral microanalysis (Ta $\neg$ ble 2) shows that at any point of the solid phase the ratio $\mathrm{Cu}^{2}+/ \mathrm{Fe}^{3}+$ equals 0.49 , i.e. close to stoichiometry (0.5), which proves composition uniformity of the obtained product.

The magnetic properties of the obtained materials were studied by means of magnetic circular dichroism (MCD)
TABLE 2. Results of X-Ray Spectral Microanalysis of Sample 4 (See Fig. 4)

\begin{tabular}{clc} 
Region of study & Element & $\begin{array}{c}\text { Elemental mass } \\
\text { fraction, \% }\end{array}$ \\
\hline 1 & $\mathrm{Fe}$ & 39.6 \\
& 0 & 26.2 \\
& $\mathrm{Cu}$ & 19.3 \\
& $\mathrm{C}$ & 11.2 \\
2 & $\mathrm{Fe}$ & 39.8 \\
& 0 & 24.7 \\
& $\mathrm{Cu}$ & 19.4 \\
& $\mathrm{C}$ & 11.6 \\
\hline
\end{tabular}

(Fig. 5a) and magnetometry (Fig. 5b). The results confirm the presence of a ferromagnetically ordered phase in the powders. The character of the curves is typical for copper ferrite and agrees with the published data $[21,22]$. Accord ing to the data of [8] the value of the saturation magnetiza tion for bulk copper ferrite is equal to $55 \mathrm{~A} \cdot \mathrm{m}^{2} / \mathrm{kg}$. In our study we obtained a product with saturation magnetization $33 \mathrm{~A} \cdot \mathrm{m}^{2} / \mathrm{kg}$, residual magnetization $15 \mathrm{~A} \cdot \mathrm{m}^{2} / \mathrm{kg}$, and $\mathrm{c}^{-}$ ercive force 5400 e. Thus, the main features of the hysteresis loop and the M C D spectrum confirm the formation of copper ferrite in the investigated samples.

So, in the course of this work the impact of different fac tors (precipitation procedure, nature of ligand) on anion-exchange synthesis of copper ferrite was established and the following optimal conditions for obtaining the product were determined: coprecipitation of copper (II) hydroxide $(0.25 \mathrm{M})$
Fig. 5. Magnetic properties of the obtained samples: a) M C D spectrum of sample 4 (see Table 1 ); $b$ ) hysteresis 100 p of sample 6 (see Table 1).
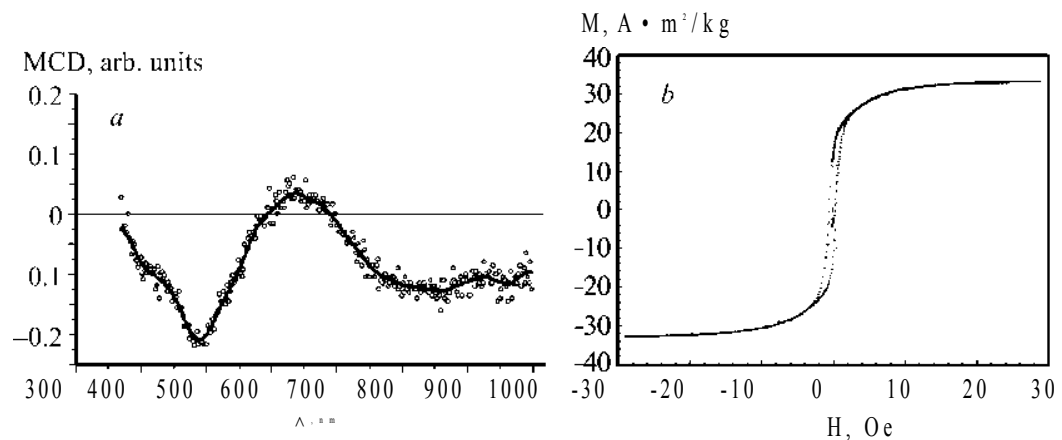
and iron (III) hydroxide $(0.25 \mathrm{M})$ from sulfate solutions using the strongly basic anionite AV-17-8 (ionite/solution molar ratio $=1: 2.5$ ) attemperature $23^{\circ} \mathrm{C}$ in the presence o f sodium tartrate for $1 \mathrm{~h}$ followed by calcination of the obtained precipitates attemperature $950^{\circ} \mathrm{C}$ for $1 \mathrm{~h}$.

The proposed method of synthesizing $\mathrm{CuFe} \mathrm{O}_{4}$ powder is convenient and easily reproduced under ordinary labora tory conditions. In addition it makes it possible to obtain pure and uniform product with reproducible physical-chemical properties.

Apparatus from the Krasnoyarsk Regional Center for Collective Use of the Siberian Branch of the Russian Academy of Sciences was used in this work.

\section{R E F E R E N C E S}

1. Yu. Sitidze and H. Sato, Ferrites [Russiantranslation], Mir, Moscow (1964).

2. I. C. Covaliu, J. Neamtua, G. Georgescua, et al., "Synthesis and characterization of ferrites $\wedge 304 / \mathrm{CuFe} 204)$ - calcium alginate hybrids for magnetic resonance imaging," $J$. Nanomater. Biostruct., 6(1), $245-252$ (2011).

3. A. A. Il'in, A. P. Il'in, N. N. Smirnov, et al., "Mechanochemical synthesis and catalytic properties o f copper ferrite," Khimiya Khimich. Tekhnol., 53(5), 86 - 90 (2010).

4. V. M. Talanov and N. P. Shabel'skaya, "Method of Producing Copper (II) Ferrite, RF Patent 2451638, No. $2010135592 / 05$," Byull. Izobr. Polezn. Modeli, No. 23 (2013), application August 25, 2010 ; published A pril 29, 2013.

5. N. Rezlescu, E. Rezlescu, F. Tudorache, and P. D. Popa, "Gas sensing properties of porous $\mathrm{Cu}-, \mathrm{Cd}$ - and Zn-ferrites," Romanian Rep. Phys., 61(2), 223 - 234 (2009)

6. T. George, S. Joseph, A. T. Sunny, and S. Mathew, "Soft chemical synthesis, magnetic and microwave studies of CuFe204 and CoFe 204," J. Metastable Nanocryst. Mater., No. 23, 141 - 152 $(2005)$.

7. I. V. Kasy Viswanath, Y. L. N. Murthy, and Kondala Rao Tata, "Synthesis and characterization of nano ferrites by citrate gel," Int. J.Chem. Sci., 11(1), 64 - 72 (2013).

8. M. Kanagaraj, P. Sathishkumar, and G. K. Selvan, "Structural and magnetic properties of $\mathrm{CuFe}_{2} \mathrm{O}$, as-prepared and thermally treated spinel nanoferrites," Indian J. Pure Appl. Phys., 52, $124-130(2014)$.

9. S. S. Kader, D. P. Paul, and S. M. Hoque, "Effect of temperature on the structural and magnetic properties of $\mathrm{CuFe}_{2} \mathrm{O}_{4}$, nano particle prepared by chemical co-precipitation method," Int. J. Mater., Mechan. Manufact., 2(1),5-8 (2014).

10. G. L. Pashkov, S. V. Saikova, and M. V. Panteleeva, "Determination of the optimal conditions for ion-exchange synthesis of cobalt (II) hydroxide using AV-17-8 anionite in OH form, "Zh. Prikl. Khim., 75(11), 1823 - 1826 (2002).

11. G. L. Pashkov, S. V. Saikova, and M. V. Panteleeva, "Anion-exchange synthesis of cobalt (II) oxalate using anionite in $\mathrm{C}_{2} \mathrm{O}$ form," Zh. Sibirsk. Federal. Univ., Ser. Khimiya, 2(2), $150-155$ (2009).

12. G. L. Pashkov, S. V. Saikova, and M. V. Panteleeva, "Anion-exchange synthesis o f cobalt hydroxide," Khim. v Interesakh Ustoich. Razv., N 0.9, 57 - 60 (2001).

13. G. L. Pashkov, S. V. Saikova, M. V. Panteleeva, et al., "Anion-exchange synthesis of nickel-containing spinel-type pigments," Steklo Keram., No. 2, $19-22$ (2014); G. L. Pashkov, S. V. Saikova, M. V. Panteleeva, et al., "Anion-exchange synthesis of nickel-containing spinel-type pigments," Glass Ceram., 71(1 - 2), 57 - 59 (2014)

14.A . Vulikh, Ion-Exchange Synthesis [i n Russian], Khimiya, Moscow (1973).

15. Powder Diffraction File: Database, JC P D S 43 - 1458; 13 - 398.

16. Powder Diffraction File: Database, JCPDS 33 - 0664.

17. Powder Diffraction File: Database, JCPDS 5- 661.

18. A. A. Lur'e, Handbook ofAnalytical Chemistry [in Russian], Khimiya, Moscow (1989).

19. S. V. Saikova, Ion-exchange Reaction Process for Extracting Non-ferrous Metals and Obtaining Disperse Materials, Author's Abstract ofDoctorals Thesis [in Russian], Siberian Federal University, Krasnoyarsk (2014).

20. K. Nakamoto, IR- and RS-Spectra ofInorganic and Coordination Compounds [Russiantranslation], Mir, Moscow (1991).

21. M. Kucera, V. Kolinsky, S. Visnovsky, and D. Chvostova, "Faraday effect in cubic and tetragonal copper ferrite $\mathrm{CuFe}{ }_{2} \mathrm{O}$ films - comparative studies," J. Magnetism Magnetic Mater., No.316, $688-691(2007)$.

22. J. Z. Jiang, G. F. Goya, and H. R. Rechenberg, "Magnetic properties of fnanostructured CuFe204," J. Phys., No. 11, 63-78 $(2000)$. 